\title{
NOS PASSOS DA PRINCESA: A DANÇA CÊNICA EM FEIRA DE SANTANA ENTRE 1950 E 1980
}

\author{
Luciano Santos do Nascimento ${ }^{1}$; Aldo José Morais Silva ${ }^{2}$ \\ 1. Bolsista FAPESB, Graduando em licenciatura em História, Universidade Estadual de Feira de Santana, e-mail: \\ lucianoperfetto@hotmail.com \\ 2. Orientador, Departamento de Ciências Humanas e Filosofia, Universidade Estadual de Feira de Santana, e-mail: \\ aldojose@gmail.com
}

PALAVRAS-CHAVE: dança cênica; campo artístico; Feira de Santana.

\section{INTRODUÇÃO}

Com o intuito de mapear as atividades nas quais a dança figurou como uma linguagem cultural e artística em Feira de Santana, entre 1950 e 1980, este trabalho busca produzir dados sobre o desenvolvimento da dança cênica, entendendo que para além de regras e padrões estéticos e técnicos, as práticas dançantes estão inseridas em convenções sociais, em coerência com seu tempo e espaço de execução (CERBINO, 2016). Identificar as pessoas que se utilizaram dessa arte e como elas dialogaram com o cenário cultural, entendendo a dança como uma arte corporal, e como tal, se faz de gestos e movimentos possibilitados pelo contexto histórico que forja o que é adequado a ser consumido e apreciado enquanto uma expressão artística e cultural (BOURDIEU, 2007). Dessa forma, pretende-se captar os passos da dança cênica nos variados espaços que essa arte pode ser disseminada.

\section{MATERIAL E MÉTODOS}

A pesquisa ganhou impulso com a análise dos exemplares do Jornal Folha do Norte dos anos de 1950 a 1980. pois o jornalismo cultural é uma forma de construir memória e faz parte da historiografia da dança. Além de trazer críticas, a agenda e as reportagens que são as principais instâncias de registro e discussão sobre a dança até a década de 1990 (CAMARGO, 2014). É nas páginas dos jornais que surgem os nomes de instituições e de pessoas que contribuíram para esse trabalho, confirmando, a partir de relatos orais e fontes imagéticas.

\section{RESULTADOS ALCANÇADOS}

A partir da pesquisa desenvolvida foi possível constatar que as práticas dançantes são evidenciadas, principalmente entre 1950 até 1957, nas escolas regulares sob a regência de docentes das áreas de educação física e música. Essas disciplinas foram regulamentadas no contexto da criação do Ministério da Educação e Saúde, pelo decreto n ${ }^{\circ}$ 18.890, em 18 de abril de 1931, durante o governo provisório de Getúlio Vargas. A dança já fazia parte das celebrações das instituições de ensino juntamente com as apresentações de piano, corais e canto desde 1939, pelo menos, quando alunos do Colégio Santanopólis realizaram encenações de sapateado, dança espanhola e bailados.

Em 1958, Hildete Galeão dos Santos, uma ex-aluna do Colégio Santanopólis, viria a fundar a primeira escola de dança de Feira de Santana. Depois de ficar parte da adolescência estudando ballet clássico na Escola Municipal de Belas Artes (EMBA) de Caxias do Sul, no Rio Grande do Sul, Hildete retornou a Feira de Santana, em 1956, e desde então lecionou aulas de dança particulares para meninas. 
Imagem 1: Hildete Galeão (ao centro) e suas alunas, 5 de julho de 1958, evento "Vale a pena Sonhar"

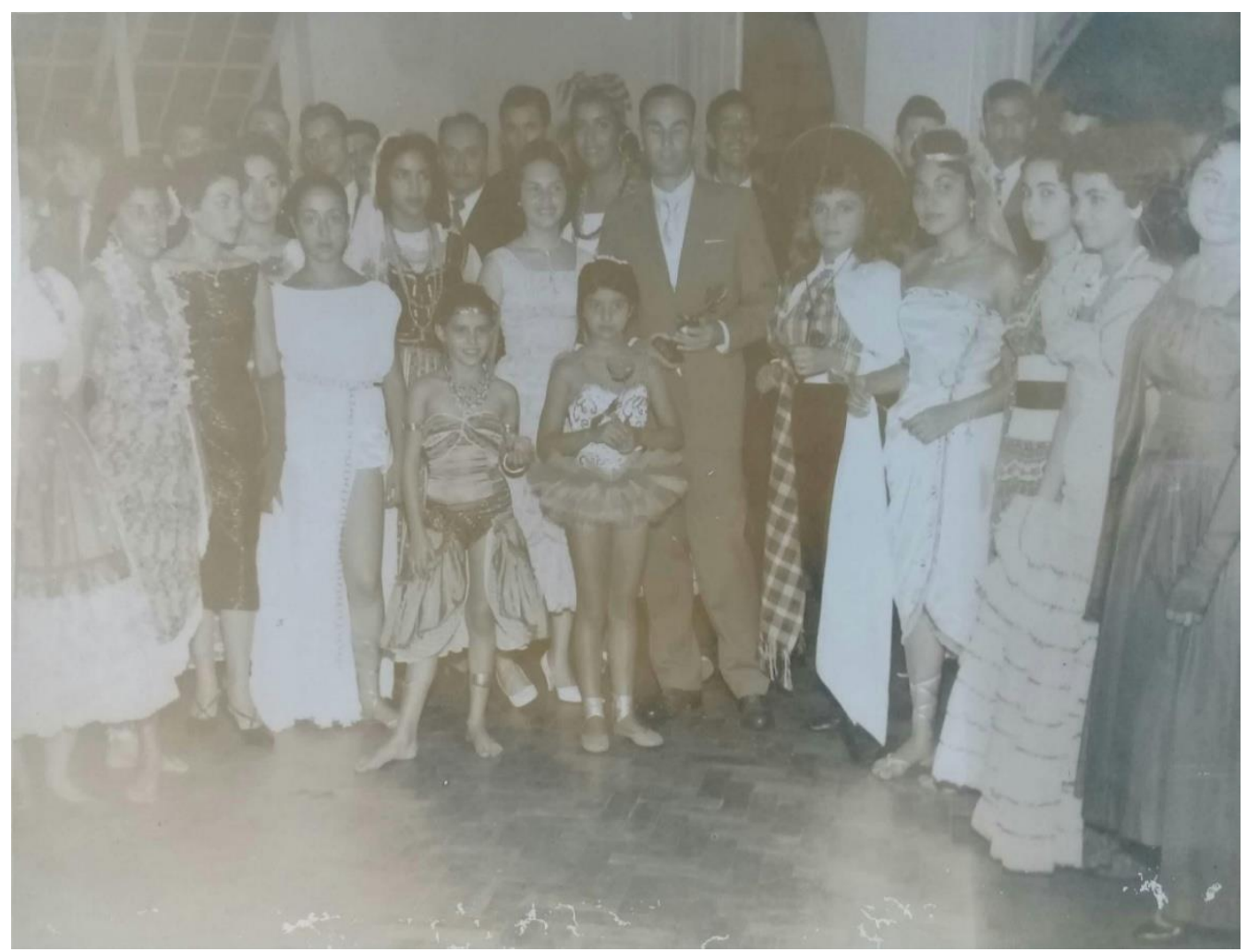

Fonte: Acervo pessoal de Hildete Galeão

O ano de 1958 foi promissor para o ensino da dança em Feira de Santana. Outros dois espaços formativos nasceram naquele ano. Um deles foi instalado no Feira Tênis Clube onde aulas eram ministradas pela professora Celina Mesquita, formada pelo Teatro Municipal do Rio de Janeiro. E o segundo, seria na Sociedade Filarmônica Euterpe Feirense, na qual o professor Clarival Souza lecionou danças de salão a senhoritas.

Concomitantemente, a Universidade Federal da Bahia (UFBA) passava, desde meados da década de 1950, por ações internas de incentivo a cursos superiores ligados à prática das diversas artes cênicas. Dessa forma, a UFBA foi a pioneira com a criação do primeiro curso de dança de nível superior do Brasil, em 1956. Sob a administração do reitor Edgar Santos, profissionais da dança expressiva alemã - entre eles Yanka Rudzka e Rolf Gelewski - foram contratados para gerir a instituição (NOGUEIRA; GUIMARÃES, 2017).

$\mathrm{Na}$ esteira deste movimento, o processo de interiorização da UFBA promoveu a criação dos Seminários Livres de Música em Feira de Santana, em 1962, que disponibilizou turmas de ballet clássico e dança moderna dirigidas por professores vinculados aquela universidade.

Neste mesmo contexto, a dança cênica ganhou outros espaços de disseminação em instituições públicas e privadas na cidade. Esse foi o caso da Escola Saci Pererê que ofereceu, além das aulas regulares, cursos extras de inglês, piano e ballet. (ESCOLINHA..., 1963, p. 3).

Na década seguinte, em 1972, foi fundada a escola de dança Earte. Funcionando até o ano de 1980 como um anexo da residência de sua diretora, a bailarina Angela Oliveira, formada em dança pela Universidade Federal da Bahia, esta instituição, desde seu início, realizou espetáculos semestrais, ocupando evidente destaque nas citações dos espaços de cultura e arte dos jornais. Em 1981, sua nova sede - um prédio de três pavimentos - foi 
construída e inaugurada ampliando as turmas de ballet clássico, dança moderna, jazz e zenyoga. A Earte propícia o ensino das técnicas da dança e vem formando bailarinas e bailarinos até os dias atuais.

Imagem 2: estudantes da escola de dança Earte, na primeira sede, 5 de maio de 1980

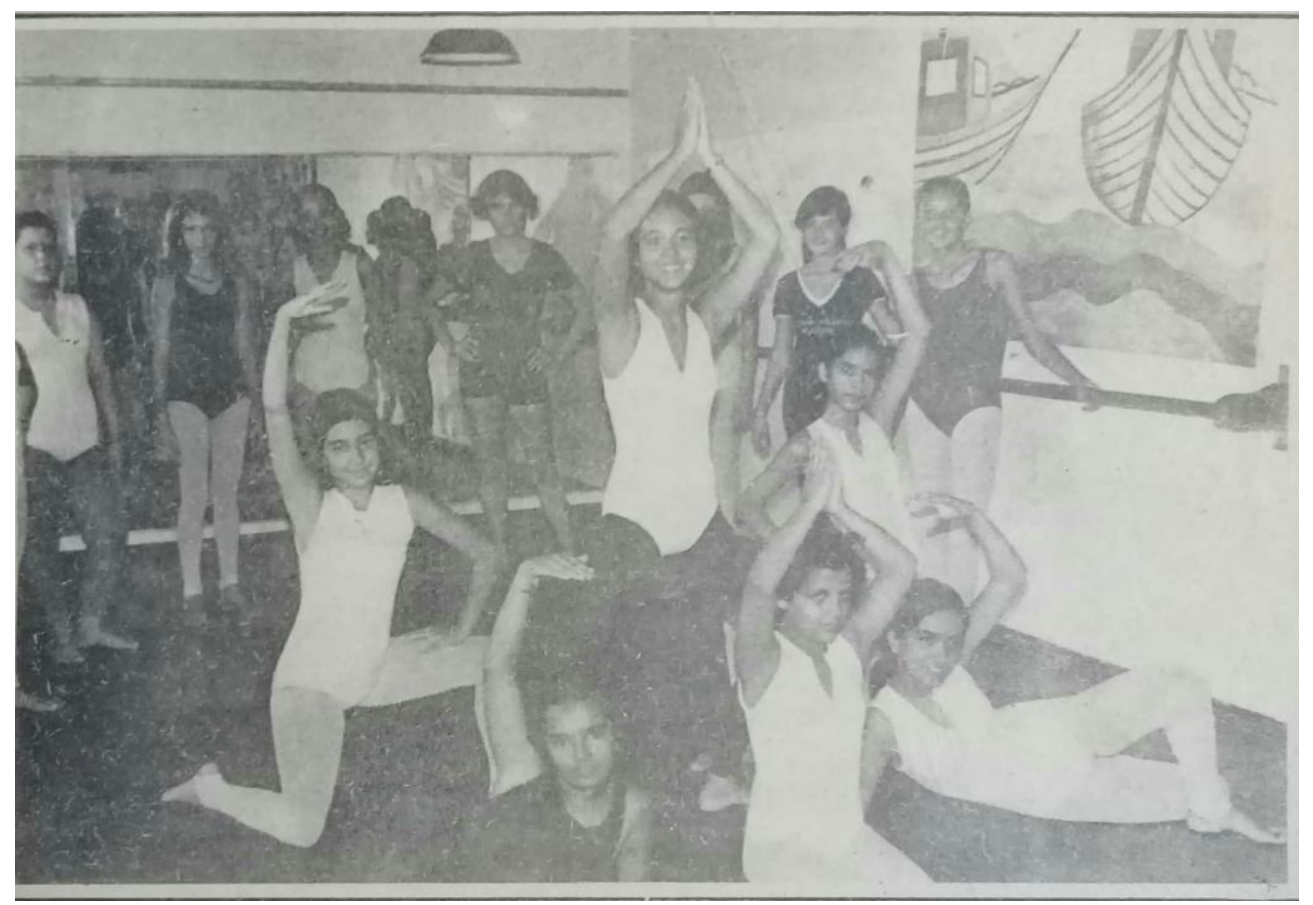

Fonte: Jornal Folha do Norte

\section{CONCLUSÃO}

Abrigando experiências da dança nas áreas recreativas, educacionais e profissionais, a comunidade feirense pôde vivenciar práticas dançantes, desde a década de 1930. A circulação de profissionais da dança cênica com formação em instituições de referência evidencia o quanto Feira de Santana pôde ter contato com produções e métodos contemporâneos ao cenário artístico e cultural vividos.

\section{REFERÊNCIAS}

BOURDIEU, P. A economia das trocas simbólicas. São Paulo: Perspectiva. 2007.

ESCOLINHA saci pererê. Folha do Norte. Feira de Santana, p.1, 16 fev. 1963.

FARO, A.J. Pequena história da dança. Rio de Janeiro: Jorge Zahar Editor. 1986.

MENDONÇA, W.N. Uma nota de arte. Folha do Norte. Feira de Santana, p.1, 18 jan. 1958.

CAMARGO, A.V.A. A dança que o jornal reporta (1984-2014): considerações sobre a dança e o jornalismo cultural no Brasil. Salvador: Revista Dança. V.3, n.2, p.11-22, jun/dez. 2014.

CERBINO, B. Dança e memória - usos que o presente faz do passado. Rio de Janeiro: Subversões de protocolo: uso impróprio. ISBN:978-85-93471-05-6. p.187-202. 2016.

NOGUEIRA, I.C.; GUIMARÃES, M.S.V.B. O projeto modernista, o moderno É a modernidade na arte da dança. In: Referenciais históricos da arte e da dança. Salvador: UFBA, escola de dança, p.34-58, 2017.

REIS, D. Ballet Stagium e o debate sobre a dança moderna brasileira no contexto sóciopolítico da década de 1970. Uberlândia: Fênix - Revista de história e estudos culturais. V.2, n.1, p.1-14, jan/mar. 2005. 